\title{
Improving the sustainability of metal-producing industries in Russia
}

\author{
Alexander Rodionov ${ }^{1}$, Marina Danilina ${ }^{1,2,3,4,{ }^{*}}$, Sofia Blagova ${ }^{4}$, Peter Godlevsky ${ }^{1}$, Nikolai \\ Pimenov ${ }^{1}$, and Stanislav Buslaev ${ }^{1}$ \\ ${ }^{1}$ Financial University under the Government of the Russian Federation, Moscow, Russia \\ ${ }^{2}$ Russian Research Institute (VNII) of Labor, Moscow, Russia \\ ${ }^{3}$ Plekhanov Russian University of Economics (PRUE), Moscow, Russia \\ ${ }^{4}$ Moscow University imeni S.Yu. Vitte (MUIV), Moscow, Russia
}

\begin{abstract}
In recent years, the metal-producing industries face a range of economic and ecological problems. The authors use content-analysis and statistical methods for analyzing the recent data and make proposals for the development $t$ of metallurgy. The metallurgical industry is in second place among all other industries in terms of atmospheric emissions. Ferrous and non-ferrous metallurgy enterprises are forced to use ore with a very low content of useful components in the extraction of metals. Thus, a huge volume of ore is supplied to beneficiation and smelting, and this, in turn, generates large quantities of waste gases from unused components. The current position of metallurgy companies in Russia does not contribute to the development of new industries for several reasons: lack of funds for the development of large plants; lack of forecast for short-term global demand for ferrous metallurgy products; a growing group of competition from foreign manufacturers for the products provided by the industry. To reduce the level of negative impact of metallurgy on the environment, it is necessary to develop and use new technologies that are safe for the environment. Unfortunately, not all enterprises use purification filters and facilities, although this is mandatory in the activities of every metallurgical enterprise.
\end{abstract}

\section{Introduction}

The metallurgical industry is a branch of heavy industry that includes the processes of making metals from ores or other materials, as well as metal alloys. The structure of the metallurgical industry includes the following processes: direct production of metals; hot and cold processing of metal products; welding; metal coating.

Metallurgy occupies a special place among many industries in Russian farms, since its share in the country's GDP is, according to various estimates, about 5\%. It is also important to note that a considerable part of the products manufactured at Russian enterprises are sent abroad $[1,2]$.

\footnotetext{
${ }^{*}$ Corresponding author: marinadanilina@yandex.ru
} 
Historically, for metallurgy in the Russian Federation, an indicator that characterizes the concentration of production is in high ranking positions. It is generally accepted that at the moment in Russia about $90 \%$ of all ferrous metallurgical products are produced by 9 companies - magnates, in contrast to non-ferrous metallurgy, where there are only 8 large enterprises. Recently, it has been especially noticeable that globalization of enterprises and companies is taking place in the metallurgical segment of the market. Huge industrial enterprises are rapidly being formed, which carry out a full cycle of metal production. This global trend in metallurgy is clearly reflected in the economy and economy of the Russian Federation.

The metallurgical industry is in second place among all other industries in terms of atmospheric emissions. Ferrous and non-ferrous metallurgy enterprises are forced to use ore with a very low content of useful components in the extraction of metals. Thus, a huge volume of ore is supplied to beneficiation and smelting, and this, in turn, generates large quantities of waste gases from unused components.

It is air pollution that is the main cause of environmental problems arising from the activities of metallurgical giants. Emissions from pipes lead to soil pollution, destruction of vegetation and the formation of man-made wastelands around large factories. In addition, the environmental problems of the domestic metallurgy are exacerbated by the high wear and tear of equipment and outdated technologies. According to the Ministry of Industry and Energy, up to $70 \%$ of all capacities in the domestic metallurgical industry are worn out, outdated and unprofitable.

Ferrous metallurgy enterprises "specialize", first of all, in carbon monoxide, which is emitted into the air by 1.5 million tons per year. Non-ferrous metal producers "prefer" sulfur dioxide, which enriches the air by 2.5 million tons annually. In total, metallurgical enterprises emit 5.5 million tons of pollutants into the atmosphere. All this ultimately falls on the heads of the residents of large metallurgical centers. There are regions for which the presence of a metallurgical plant is becoming the main, if not the only, environmental problem. Large metallurgical centers - Kemerovo, Lipetsk, Magnitogorsk and Novokuznetsk - are included in the list of cities with the highest level of air pollution. The aerogenic load of pollutants in the cities of Orsk and Novotroitsk was $0.71 \mathrm{t} /$ inhabitant and $1.9 \mathrm{t} / \mathrm{m} 2,0.83 \mathrm{t} /$ inhabitant and $1.7 \mathrm{t} / \mathrm{m} 2$, respectively. Not only atmospheric air, but also surface and underground waters and soil suffer from the activities of metallurgical enterprises $[1,2]$.

Metallurgy, in particular ferrous, has the most serious impact on the environment. Metallurgy is an energy and resource intensive industry. With an annual consumption of several thousand tons of mineral resources, no more than $30 \%$ goes into the final product, the rest is formed by production waste.

So, a full-cycle metallurgical plant with a capacity of 10 million tons of steel per year, before the introduction of strict control, emitted more than 200 thousand tons of dust, 50 thousand tons of sulfur compounds, 250 thousand tons of carbon monoxide, nitrogen oxides, etc. substances. The dust concentration in emissions reached $50-120 \mathrm{~kg} / \mathrm{t}$ of the steel produced. In advanced metallurgical processes, these emissions are reduced to $10 \mathrm{~kg} /$ $\mathrm{t}$ of steel $[1,2]$.

The gaseous emissions of metallurgical plants are about $2500 \mathrm{~m} 3 / \mathrm{t}$ of steel. The sources of sulfur compounds emitted into the atmosphere are mainly coke (40-60\%) and ore $(5-30 \%)$. With slags, $45-55 \%$ of sulfur is removed from metallurgical units, and up to $6 \%$ of sulfur is transferred to steel products, the rest of the sulfur is emitted into the atmosphere. Agglomeration is the main source of $\mathrm{SO} 2$ emissions (45-55\% of total $\mathrm{SO} 2$ emissions). A significant amount of $\mathrm{SO} 2$ or $\mathrm{H} 2 \mathrm{~S}$ is emitted into the atmosphere during cooling and slag processing (10-35\%). The rest of the SO2 is released into the environment from the pipes of boiler plants, steel mills and rolling mills $[1,2]$. 
Hydrogen cyanide $\mathrm{HCN}$ is present mainly in blast furnace gas. Its concentration is, $\mathrm{mg} /$ $\mathrm{m} 3$ : in the production of pig iron 200-400, in the production of mirror cast iron 300-400 and in the production of ferromanganese 1500-3500. Emissions of hydrogen cyanide from coke plant units can reach $0.5 \mathrm{~kg} / \mathrm{t}$ of coke $[1,2]$.

Nitrogen oxides are formed in blast-furnace, open-hearth and heating furnaces, in coke ovens and in steam boilers. In blast furnaces, the source of nitrogen oxide emissions is blast furnace air heaters, in the exhaust gases of which the content of NOx is (1.7 h6.6) $\cdot 10-4 \%$. The concentration of nitrogen oxides in the vertical channels of open-hearth furnaces when heating without intensifiers is on average $0.03 \%$; when oxygen is supplied, it increases to $0.1 \%$ and in some cases reaches $0.25 \%$. The average amount of nitrogen oxide emissions is $2.5 \mathrm{~kg} / \mathrm{t}$ of steel $[1,2]$.

\section{Materials and Methods}

The current research uses statistical data and methods in order to analyze the situation in the sphere of ecological and biological development on the basis of the main indicators. Among these indicators were chosen the amounts of emissions of the most common air pollutants outgoing from stationary sources, the current (operating) costs of environmental protection. The table 1 shows the emissions of the most common air pollutants outgoing from stationary sources in 2016-2019. Gaseous and liquid substances were the most significant emissions, the largest part of them belonged to sulfur, nitrogen oxides and monoxide hydrocarbons.

Table 1. Emissions of the most common air pollutants outgoing from stationary sources, in the Russian Federation (thousand tons).

\begin{tabular}{|c|c|c|c|c|c|c|c|c|}
\hline & & \multicolumn{6}{|c|}{ Including: } \\
\cline { 5 - 9 } & Total & solids & $\begin{array}{c}\text { gaseous and } \\
\text { liquid } \\
\text { substances }\end{array}$ & sulfur & $\begin{array}{c}\text { dioxide } \\
\text { carbon }\end{array}$ & $\begin{array}{c}\text { nitrogen } \\
\text { oxides }\end{array}$ & $\begin{array}{c}\text { monoxide } \\
\text { hydrocarbons } \\
\text { (no VOCs) }\end{array}$ & $\begin{array}{c}\text { volatile } \\
\text { organic } \\
\text { compounds }\end{array}$ \\
\hline 2016 & 17349.3 & 1723.9 & 15625.4 & 4011.4 & 1830.1 & 4907.1 & 3406.1 & 1304.6 \\
\hline 2017 & 17477.5 & 1728.9 & 15748.5 & 3700.5 & 1879.4 & 4950.3 & 3783.1 & 1254.5 \\
\hline 2018 & 17068.1 & 1509.0 & 15559.1 & 3617.0 & 1770.7 & 4868.4 & 3805.3 & 1335.7 \\
\hline 2019 & 17295.1 & 1611.3 & 15683.7 & 3676.7 & 1799.0 & 4834.6 & 3953.3 & 1271.5 \\
\hline
\end{tabular}

Source: [1] Rosstat.

Metallurgy is the largest industry, but, like other areas of the economy, has a negative impact on the environment. Over the years, this influence leads to pollution of water, air, soil, which entails climate change.

Air emissions

A key problem in metallurgy is considered to be that harmful chemical elements and compounds get into the air. They are released during fuel combustion and processing of raw materials. Depending on the specifics of production, the following pollutants enter the atmosphere:

carbon dioxide; aluminum; arsenic; hydrogen sulfide; mercury; antimony; sulfur; tin; nitrogen; lead, etc.

Experts note that every year, due to the work of metallurgical plants, at least 100 million tons of sulfur dioxide are released into the air. When it enters the atmosphere, it subsequently falls to the ground in the form of acid rains, which pollute everything around: trees, houses, streets, soil, fields, rivers, seas and lakes. 


\section{Industrial wastewater}

The actual problem of metallurgy is the pollution of water bodies with industrial effluents. The point is that water resources are used at various stages of metallurgical production. During these processes, the water is saturated with phenols and acids, coarse impurities and cyanides, arsenic and cresol. Before such effluents are discharged into water bodies, they are rarely purified, therefore all this "cocktail" of chemical precipitation of metallurgy is washed off in the water area of cities. After that, water saturated with these compounds, not only cannot be drunk, but also used for domestic purposes [2].

Consequences of biosphere pollution

Environmental pollution by the metallurgical industry, first of all, leads to a deterioration in public health. The worst of all is the condition of those people who work in such enterprises. They develop chronic illnesses that often lead to disability and death. Also, all people living near factories eventually get serious illnesses, as they are forced to breathe dirty air and drink poor quality water, and pesticides, heavy metals and nitrates enter the body.

At the moment, the current (operating) costs of environmental protection are not at the proper level. This creates problems for the ecological and biological development of the country. The detailed analysis of the current (operating) costs of environmental protection in the Russian Federation on 24.04.2020 (table 2) shows that amount of costs constantly grew in almost all types of costs except for research and development activities to reduce negative anthropogenic impacts on the environment where the amount of costs started to diminish from 2013. The total amount of current (operating) costs of environmental protection in 2019 reached 374411 million rubles [1, 2].

Table 2. Current (operating) costs of environmental protection in the Russian Federation on 24.04.2020 (at actual prices; million rubles).

\begin{tabular}{|c|c|c|c|c|c|c|c|c|c|c|}
\hline & & \multicolumn{9}{|c|}{ Including: } \\
\hline & 褐 & 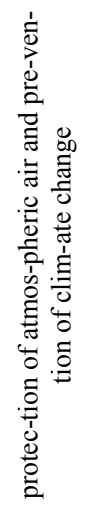 & 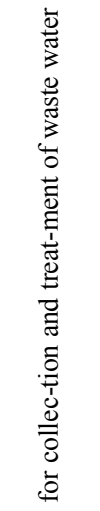 & 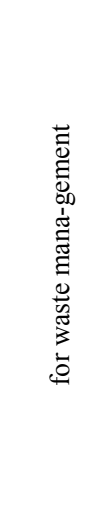 & 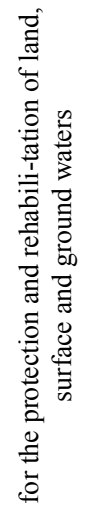 & 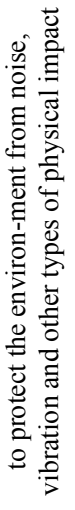 & 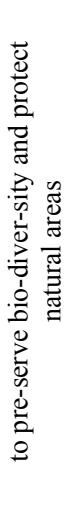 & 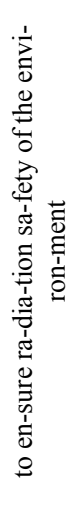 & 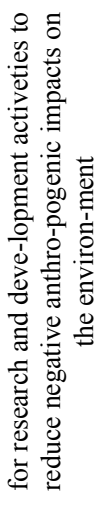 & 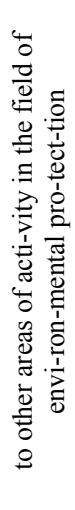 \\
\hline 2012 & 239170 & 47062 & 121332 & 45798 & 13701 & 262 & 534 & 4795 & 460 & 5225 \\
\hline 2013 & 254377 & 44800 & 132818 & 50402 & 15337 & 273 & 314 & 5342 & 1022 & 4069 \\
\hline 2014 & 269838 & 50920 & 136468 & 55702 & 15266 & 308 & 350 & 6088 & 937 & 3799 \\
\hline 2015 & 292074 & 58250 & 145147 & 60256 & 16660 & 289 & 336 & 5459 & 582 & 5096 \\
\hline 2016 & 306534 & 56851 & 154313 & 63580 & 19526 & 357 & 396 & 5843 & 647 & 5022 \\
\hline 2017 & 320947 & 56906 & 163261 & 70041 & 15452 & 289 & 422 & 6328 & 464 & 7783 \\
\hline 2018 & 345464 & 61075 & 173688 & 79885 & 15347 & 381 & 514 & 7728 & 205 & 6641 \\
\hline
\end{tabular}




\begin{tabular}{|l|l|l|l|l|l|l|l|l|l|l|}
\hline 2019 & 374411 & 63760 & 174921 & 102396 & 16348 & 354 & 639 & 8266 & 219 & 7506 \\
\hline
\end{tabular}

Source: [1] Rosstat.

Mining sub-industry.

Domestic primary raw materials (ore) resources in the bulk do not meet the requirements:

the world market, and their regional location makes export supplies difficult due to high transportation costs. Opportunities for the growth of export supplies of commercial ore were exhausted in the early $90 \mathrm{~s}$. The further increase in the export of primary raw materials was hampered by many factors [3]:

* saturation of the world market with mining raw materials and existing principles providing transnational corporations with raw materials (from the fields under their control);

* production and technological features of the mining industry in Russia (low specific gravity of the pellets). Most countries developing metallurgy give preference to secondary or metallized raw materials. This predetermined a significant increase in the share of scrap metal and pellets in the structure of raw materials exported by Russia;

* fast pace of recovery of domestic metallurgical production based on primary raw materials.

Over the past few years in Russia, including at the state level, the idea of the need to restructure the entire ferrous metallurgy industry has begun to take root, starting with forecasting the need for a range of products and ending with the location of production on the territory, including the creation of medium-sized industries (mini-factories) that form "Mobile" offer in the industry for key market positions.

The search for directions for the effective development of the competitiveness of the metallurgical industry, taking into account the Russian peculiarities of the territorial distribution of production facilities, is becoming one of the priorities for the development of the national economy today.

The Russian ferrous metallurgy currently has its own unique path of development, which was laid down in the Soviet Union and was partially adapted to current market realities. Partial adaptation is manifested in the satisfaction of only some commodity items that are in domestic demand, while the inherited enterprises are mostly export-oriented.

Significant restrictions in the modernization of the ferrous metallurgy industry are: lack of own investment resources, restrictions on attracting foreign investment, lack of longterm bank loans for a period of 10 to 30 years, rupture of internal economic ties between former intra-union countries [3].

The current position of ferrous metallurgy companies in Russia does not contribute to the development of new industries for several reasons: lack of funds for the development of large plants; lack of forecast for short-term global demand for ferrous metallurgy products; a growing group of competition from foreign manufacturers for the products provided by the industry.

At the same time, the modernization of the ferrous metallurgy industry is important for the Russian Federation, since this industry is not only basic for many other industries, such as mechanical engineering, construction, oil and gas complex, etc., but also belongs to strategic industries, since the military depends on it. -industrial complex and security of the country as a whole. The loss of the market for a part of the nomenclature due to competition or for other reasons may entail a threat to the country's defense complex.

A feature of the modernization of the national ferrous metallurgy is that this process should proceed in the "advanced development" mode, when the technologies being introduced are ahead of competing countries in development in the long term. The "catchup" path, of course, would be a simpler form of modernization of the domestic ferrous 
metallurgy industry, since it would make it possible to directly use the developments of developed countries, which would avoid many mistakes.

Nevertheless, the study of the international experience of modernizing the national production of ferrous metallurgy remains an urgent task, however, it is necessary to look for your own way of modernizing the industry, providing it with "advanced development".

The innovation activity of the enterprise should include both the development and implementation of new types of goods and services, technologies, and the development of new methods and methods of production and management. The development of innovative activities largely depends on the participation, motivation and incentives of employees in production processes [4].

With this consideration, innovative development appears to be one of the main directions of modernization. This direction is acquiring a comprehensive character, innovations are used not only in the technical sphere of activity, but also in the structural and organizational one.

It is important to note that in the world practice, all existing elements are included in the innovation process in the ferrous metallurgy industry, from development to the introduction of a product into the market. World leaders in the industry are constantly looking for ways to improve production efficiency through the introduction of new types of equipment, developments and technologies.

Changes in production technology, equipment, demand for products have led to a largescale modernization of enterprises in developed countries - minimization and specialization of production, placement near sources of raw materials or end consumers, focus on demand and consumer orders. The most significant change was the creation of mini-metallurgical plants with a capacity of up to 1.5 million tons of products per year, requiring significantly less capital investments and implementation time [1,2].

Mini-metallurgical plants are a fundamentally new model of doing business in comparison with classic plants. Let's list the main innovative features of mini-metallurgical plants.

The characteristic features of mini-factories include their preferential location in close proximity to consumers of finished products and resources of metal scrap formed directly in the region where the enterprise is located, as well as the intensive use of the ready-made infrastructure of the region, which leads to a reduction in transport costs and capital investments in 4-7 time [3].

Mini-metallurgical plants (minimill) include modern electric steel-making complexes of both small capacity (10-50 thousand tons of steel per year), and plants with a capacity of 12 million tons of products per year. Mini-plants for the production of steel, as a rule, operate on an incomplete metallurgical cycle and use scrap of ferrous metals, direct reduced iron and pig iron as feedstock, which makes them different from large metallurgical plants, the raw material for which is ore. At such enterprises, there is no extremely energyintensive coke-blast-furnace production, which favorably distinguishes mini-plants from full-cycle enterprises $[1,2]$.

The modular construction of production at mini-factories leads to a significant reduction in the costs of organizing it - from 20 to $60 \%$ in comparison with full-cycle metallurgical plants, as well as to a reduction in the development time of production capacities, which is 1.5-2 years (for full-cycle plants, the time to reach full capacity can reach 7-10 years). In addition, the production modules of the mini-plant can be located on areas (18-20 hectares per 1 million tons of steel per year), 8-15 times less than those required for the construction of a metallurgical plant $[1,2]$.

Modernization of the ferrous metallurgy industry in terms of the development of the metallurgical base in new regions (Eastern Siberia and the Far East), while providing the products of the metallurgical industry for new capital-intensive construction projects (the 
development of the Trans-Siberian Railway, the Vostochny cosmodrome), as well as the construction of large strategic projects, such as, for example, the reconstruction of the Trans-Siberian and Baikal-Amur main lines can go through the construction of minifactories. The construction of new plants in these regions will in itself entail the need to create a transport infrastructure for them, and the transport industry is a large consumer of metal. Thus, a "mutually pollinated" stimulation of both branches of the national economy can occur.

The transition to mini-factories must begin with production, with the demand for cheap groups of goods (for builders) with the subsequent complication of the technological line. In the future, it will be possible to master the production of more complex and profitable products, for example, beams, channels, pipes, flat products. The transition from one group of products to another, judging by world experience, is usually accompanied by a shortterm extraction of super-profits, which makes it possible to obtain our own investment reserves for further modernization and expansion of production [5].

As a result, it can be stated that a step-by-step modernization path is possible for Russia, which consists not in a one-stage modernization of the entire industry as a whole, but in gradual - starting from its most dynamic part - mini steel mills and direct reduction iron production plants. The choice of this direction is due to the many advantages of the concept of development of such plants, which have already been repeatedly confirmed by the practice of leading countries.

\section{Results}

For the further environmentally friendly development of metallurgy, it is necessary to develop proposals to stimulate the introduction of resource-saving and environmental technologies at the enterprises of the mining and metallurgical complex. In order to carry out an effective modernization of production facilities, it is necessary to create conditions for the transition of the metallurgical industry to an innovative path of development.

A number of institutes are actively involved in the innovation activities of the industry enterprises, carrying out the most important projects of reconstruction and technical reequipment (introduction of continuous casting machines, electric smelting of ferrous and non-ferrous metals, electrolysis of aluminum, copper, zinc, galvanizing and aluminizing technology of rolled steel, etc. equipment for the production of large-diameter pipes LDP). This is facilitated by the high and internationally recognized level of scientific schools, state scientific centers (SSC).

Currently, there are only nine federal state unitary enterprises in Russia - research institutes out of the sixty-one that existed before.

Considering that in Russia almost all metallurgical enterprises are privately owned, when implementing an innovation policy, reconstruction and modernization of production in order to increase the competitiveness of products, it is necessary to ensure the observance of state interests in the field of resource and energy conservation, reducing the anthropogenic load on the natural environment, strategic forecasting the development of the industry, determining the state technical and technological policy in metallurgy, developing projects of the corresponding federal or other state programs, concepts and other strategic documents, which determine the development of metallurgy.

In this regard, it is necessary to work out the issue of creating a Federal Center for Science and High Technologies in the field of metallurgy and to prepare appropriate proposals to the Interdepartmental Commission on Science and Innovation Policy.

In order to increase the competitiveness of the Russian metallurgy in the industry, favorable conditions must be created for the implementation of innovative projects of particular importance to the state. 
These projects include the investment project "Development and Industrial Development of the Corrosion Protection Technology of Metal Structures by Chemical Thermal Modification".

Modernization and restructuring of metallurgical enterprises are closely related to the solution of social problems arising from the release of workers. The main ways to solve them include the implementation of measures aimed at additional social support for laid off workers at the expense of the employers' direct capabilities:

-an increase by employers (depending on the categories of workers and working conditions) in the amount of one-time financial assistance to laid-off workers for independent job search;

-early retirement;

-organization of professional retraining of released workers;

-creation of acceptable non-subsidized jobs (in parallel with the process of laying off workers) and production of non-core products; organization of their own entrepreneurial activities by the released workers;

-support for the creation of small businesses that create new jobs.

Increasing the effectiveness of interaction between government agencies and business structures in the production of metal products involves:

-industrial and energy Foresight;

-conducting applied economic research in priority areas of the complex's strategic development;

-reforming the system of professional training of personnel and its harmonization with world practice;

-improvement of the system of qualification requirements for the jobs and professions of workers, the positions of managers and specialists of the complex;

-development of a system of social partnership - first of all, at the regional level;

f-urther implementation of structural reforms in the metallurgical complex (technological changes in the structure of production, types of products, etc.);

-coordination of work on forecasting the development of related industries and regions.

To increase the reliability and validity of forecasts for the development of industries, it is necessary to: a strategy of territorial development of Russia for the long term, first of all a promising layout of productive forces; long-term forecast of the socio-economic development of Russia; Russian foreign trade development strategy, taking into account the state of the global economic environment, assessment of Russia's competitive advantages in the world market, volumes of exports and imports, the degree of Russia's integration into the international economic space; the main provisions of the demographic and migration policy of the Russian Federation; transport and energy balance, which should become the main tool for identifying imbalances in the forecasting process.

In this regard, it is necessary to coordinate plans for the development of enterprises of the mining and metallurgical complex with the General Schemes for the location of electric power facilities, the development of pipeline transport and the railway network, and development strategies for other industries and regions of Russia.

It is also advisable to develop a program to meet the needs of enterprises of the militaryindustrial complex in special products of the metallurgical industry, including the development of the production of high-tech products based on titanium and magnesium alloys and materials.

\section{Discussion}

When analyzing the "market" of metal in Russia, most economists dealing with macroeconomic problems adhere to traditional approaches to the study of the development 
of metallurgy (as it should be under the created general economic conditions). The analysis is reduced to the study of financial and economic processes. At the same time, the influence of regional, technological and institutional factors on metallurgy is ignored.

In the 1990s, studies of micro-level processes, carried out by metallurgical companies with the involvement of domestic and foreign specialists, became widespread. In works on the study of the financial and economic activities of metallurgical companies, the main attention is paid to the analysis of current economic problems and ways to solve them, without paying due attention to macroeconomics.

Comprehensive sectoral studies have a special specificity - it is necessary to take into account all the main prerequisites and limitations. They integrate the influence on the development of metallurgy of the most significant factors of macroeconomic policy and restrictions on the processes of economic development on the part of operating metallurgical enterprises. Along with the data of macroeconomic statistics and generalized sectoral indicators, information on the activities of metallurgical enterprises is involved, that is, on the work of metallurgy as a single complex.

\section{Conclusions}

To reduce the level of negative impact of metallurgy on the environment, it is necessary to develop and use new technologies that are safe for the environment. Unfortunately, not all enterprises use purification filters and facilities, although this is mandatory in the activities of every metallurgical enterprise.

In addition, it is necessary to develop a set of measures aimed at increasing the depth of processing of mineral resources for the metallurgical industry, the implementation of which will help to increase the recovery of useful components, reduce production costs, reduce the negative impact on the environment and increase the competitiveness of metal products.

All leading metallurgical companies carry out extensive investment programs using their own and borrowed funds, aimed at bringing the quality of products to the requirements of the world market, automating and computerizing technological processes, in related industries, as well as in developing the raw material base. Nevertheless, the conditions of the present time, especially on the eve of accession to the WTO, require the strengthening of this process.

The implementation of the already launched production restructuring programs will increase the output of competitive (including import-substituting) products with a high share of added value and with a corresponding increase in the level of consumer properties.

\section{References}

1. Rosstat, official site (2020) www.rosstat.gov.ru

2. Russian Metals Industry 2020-2024, https://www.reportlinker.com/

3. K.G. Berden, O. Yastrebova, Background report on the Russian Steel sector Sector structure and government policies (2011) https://www.researchgate.net/publication/303298425_Background_report_on_the_ Russian_Steel_sector_-_Sector_structure_and_government_policies, DOI:10.13140/RG.2.1. $\overline{3} 819.35 \overline{2} 6$

4. V.A. Dolinskii, L.D. Nikitin, A.A. Odintsov, K.I. Domnin, Recycling wastes in sinter and hot-metal production, (2010) https://link.springer.com/article/10.3103/S0967091210080061 
5. D. Elagina Leading metallurgical companies in Russia in H1 2019, by production, https:/www.statista.com/statistics/1079897/leading-metallurgical-companies-byproduction-russia/, Sep 23, 2020 